\title{
TEG's Utility to Detect Hypercoagulability in Adult Patients at Post-Cardiac Surgery Using Cardiopulmonary Bypass in ICU
}

\author{
Hildegardis Dyna RD ${ }^{1}$, Hartono Kahar ${ }^{1}$, Arifoel Hajat ${ }^{1}$, Philia Setiawan ${ }^{2}$, Heroe Soebroto ${ }^{3}$ \\ ${ }^{1}$ Department of Clinical Pathology, Faculty of Medicine, Airlangga University/Dr. Soetomo Hospital, Surabaya, Indonesia. E-mail: \\ dr.dynarsal@gmail.com \\ ${ }^{2}$ Department of Anesthesiology and Reanimation, Faculty of Medicine, Airlangga University/Dr. Soetomo Hospital, Surabaya, Indonesia \\ ${ }^{3}$ Department of Cardiovascular and Thoracic Surgery, Faculty of Medicine, Airlangga University/Dr. Soetomo Hospital, Surabaya, Indonesia
}

\begin{abstract}
The use of Cardiopulmonary Bypass (CPB) in adult patients of cardiac surgery disrupts the coagulation system. The most common complication of the coagulation system is bleeding; however, that does not rule out the possibility of a dangerous hypercoagulation condition. A quick and precise coagulation test can provide clues for clinicians to predict future hemostatic disorders or determine interventional therapy. aPTT and PT are standard laboratory tests, which are limited to detect a deficiency of coagulation factors. Thromboelastography (TEG) test ( $R$ time, $K$ time, $\alpha$ angle, MA, and LY30) provides an overview of the entire coagulation and fibrinolysis process with faster results. A $2.7 \mathrm{~mL}$ citrate blood sample was taken

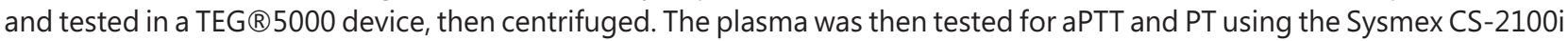
device. Bleeding volume was measured from chest drain 1-2 hours in the ICU after chest closure in the operating room. Bleeding criteria were as follows: $>1.5 \mathrm{~mL} / \mathrm{kg} /$ hour for 6 hours consecutively in 24 hours or $>100 \mathrm{~mL} /$ hour. The results showed 30 patients with no clinically significant bleeding. A significant correlation was found between PT and bleeding volume at IV hour $(p=0.008, r=0.472)$. There was no correlation between aPTT and TEG ( $R$ time, $K$ time, $\alpha$ angle, MA, and LY30) with the bleeding volume at I, II, III, and IV hours. There was a hypercoagulation indication of the TEG test of $56.7 \%$, which showed clinical importance for the patient. PT can be used to analyze changes in bleeding volume at IV hour and TEG is more superior to detect hypercoagulability of adult patients after cardiac surgery with CPB.
\end{abstract}

Keywords: Bleeding volume, aPTT, PT, TEG, R time, K time, $\alpha$ angle, MA, LY30

\section{INTRODUCTION}

Cardiopulmonary Bypass (CPB) is an extracorporeal circuit used to assist hemodynamic circulation and respiration with temperature regulation to facilitate cardiac and large vessel surgery. Cardiopulmonary bypass is often used in open-heart surgery procedures. However, this device can cause hemostatic system disorders. This is due to the direct contact between blood and the surface of the appliance, the duration of CPB use, hemodilution, the use of anti-platelets and/or pre-operative anticoagulants, heparinization during $\mathrm{CPB}$, and hypothermic condition. ${ }^{1-3}$

Complications, which follows after the use of CPB is bleeding or thrombosis. Massive and continuous bleeding requires administration of blood component therapy. Often, in certain circumstances, it even requires a re-operative surgery. Bleeding of insignificant volume does not require interventional therapy. Hypercoagulation conditions due to complications of CPB use can also occur. ${ }^{4}$
Thrombosis is a manifestation of the hypercoagulation condition after cardiac surgery with $\mathrm{CPB}$, although the incidence is rare. However, this situation is a serious problem that endangers patient safety. $^{5}$

The data from the Department of Thorax Cardiovascular Surgery at Dr. Soetomo Hospital in 2019 showed that $99.7 \%$ and $96.5 \%$ of open-heart surgeries required CPB in 2017 and 2018, respectively. This indicates the high possibility of hemostatic disorders due to the use of CPB.

Appropriate hemostatic tests are required to detect hemostatic disorders in post-cardiac surgery patients using CPB. The physiological coagulation tests, which are routinely used at the Dr. Soetomo Regional Hospital are the activated partial thromboplastin time (aPTT) and prothrombin time (PT). The long waiting time for the results of aPTT and PT examinations causes limitations in real-time monitoring, causing a frequent delay in giving therapy if the results are abnormal. ${ }^{1,6}$ Another drawback of this test is the possibility to be affected 
by several conditions such as hemolysis, hyperbilirubinemia, and lipemia. This limitation of aPTT and PT tests make it difficult to provide intervention therapy in conditions of massive bleeding, which requires fast results. ${ }^{7}$

Thromboelastography (TEG) is a Point of Care Testing (POCT), which can assess the entire process from formation, strength, stability, and breakdown through measurement of clot formation, platelet function, platelet-fibrinogen interactions, and fibrinolysis. TEG examination has real-time monitoring with a relatively shorter waiting time for results. The clinician can directly view the graph of the coagulation and fibrinolysis formation process through the monitor screen by looking at the parameters $\mathrm{R}$ time, $\mathrm{K}$ time, $\alpha$ angle, $\mathrm{MA}$, and $\mathrm{LY} 30,{ }^{8,9}$ TEG helps clinicians determine when to start therapy, especially in surgery using CPB. TEG can also differentiate whether bleeding is from an operative wound or coagulopathy. ${ }^{8,9}$ However, TEG has several limitations; in addition to its relatively more expensive cost, TEG has not specifically assessed the deficiency, which emerges from intrinsic or extrinsic coagulation factors. In addition, this assay is not widely used in many hospitals.

This study aimed to analyze the relationship between aPTT, PT, and TEG values with bleeding volume in adult patients after open-heart surgery with CPB.

\section{METHODS}

This research was conducted from July 2019 until December 2019. The research was carried out at Dr. Soetomo Hospital: Integrated Cardiac Service Center, ICU of Integrated Central Surgery Building, and Clinical Pathology Laboratory. The study design was a prospective observational.

The study subjects were post-cardiac surgery patients with CPB at 1-2 hours in the ICU post-sternal closure. Patients over 18 years were included in the inclusion criteria. Patients who underwent re-operative surgery were excluded. A total of $2.7 \mathrm{~mL}$ blood sample was taken with an aseptic procedure into a citrate tube and then examined with the TEG $® 5000$ device. Then the sample was centrifuged at $1500 \mathrm{G}$ for 15 minutes, the plasma was then examined for aPTT and PT with Sysmex CS-2100i device. Bleeding volume was measured from the chest drain in the ICU starting 1-2 hours in place after chest closure. Bleeding criteria: $>1.5 \mathrm{~mL} / \mathrm{kg} /$ hour in 6 hours consecutively for 24 hours or $100 \mathrm{~mL} /$ hour.

This study has been approved by the Health
Research Ethics Committee of Dr. Soetomo Hospital, Faculty of Medicine, Airlangga University, Surabaya with number 1342/KEPK/VII/2019.

The results of the TEG, aPTT, and PT tests were analyzed with a statistical test using SPSS version 17.0. The results will be tested for data normality using Shapiro-Wilk. Data with normal distribution were analyzed with the Pearson correlation test and data with abnormal distribution were analyzed with the Spearman correlation test with a significance level of $p<0.05$.

\section{RESULTS AND DISCUSSIONS}

Patient characteristics are listed in Table 1. The results of this study showed that 10 patients (33.3\%) experienced an increase in the bleeding volume from I hour to IV hours, while 4 patients (13.3\%) experienced an increase in bleeding volume from III hours to IV hours. The mean bleeding volume in I, II, III, and IV hours was $16.33 \mathrm{~mL}(\mathrm{SD} \pm 14.767 \mathrm{~mL}), 14.77$ $\mathrm{mL}(\mathrm{SD} \pm 10.559 \mathrm{~mL}), 21.90 \mathrm{~mL}(\mathrm{SD} \pm 20.471 \mathrm{~mL})$, and $18.33 \mathrm{~mL}$ (SD $\pm 15.020 \mathrm{~mL}$ ) (Figure 1).

Based on the criteria of Colson et al. the bleeding that was considered clinically significant was $>1.5$ $\mathrm{mL} / \mathrm{kg} / \mathrm{hour}$ for 6 consecutive hours within 24 hours. ${ }^{10}$ However, according to Bojar's criteria, the amount of bleeding was $>100 \mathrm{~mL} /$ hour. ${ }^{4}$ The results of this study indicated that none of all subjects had the number of bleeding volumes, which met the two criteria above, either at I, II, III, or IV hours.

The aPTT test showed normal results (23-33 seconds) in 11 patients or $36.7 \%$ of the total study subjects and aPTT > 33 seconds in 19 patients or $63.3 \%$. The median value was 37.7 seconds (minimum 18.5 seconds, maximum 67.2 seconds). Five cases or $16.67 \%$ of the total sample showed a prolonged aPTT value up to $\geq 1.5$ times the upper limit of normal value according to the criteria of Haas et $a l .{ }^{11}$ These results did not indicate bleeding that met the criteria of Colson et al. and Bojar et al., which require the provision of special therapy or intervention. ${ }^{4,10}$ The results of the PT test showed normal results (9-12 seconds) in 20 patients or $66.7 \%$ and PT > 12 seconds ( $<1.5$ times the upper normal limit) in 10 patients or $33.3 \%$. The median value was 11.4 seconds (minimum of 9.5 seconds, maximum 15.4 seconds). Prolonged PT value with the criteria $\geq 1.5$ times the upper limit of normal according to the criteria of Haas et al. was not found in this study. ${ }^{11}$

The results of the Spearman correlation test showed that the APTT value was not significantly correlated with bleeding volume at I, II, III, and IV 
hours ( $p>0.05)$. The results of the Mann-Whitney test showed that there was no significant correlation between the prolonged aPTT values according to the criteria of Haas et al. with the bleeding volume at I, II, III, and IV hours $(p>0.05){ }^{11}$

The results of the Spearman correlation test showed that there was a significant correlation between the PT value and the volume of bleeding at IV hour $(p<0.05)$ with a positive direction and moderate correlation, but there was no significant correlation between the PT value and the volume of bleeding at I, II, and III hours. ( $p>0.05)$.

Table 1. Demographics and characteristics of perioperative patient

\begin{tabular}{|c|c|c|c|}
\hline Patient Demographics & Frequency & Mean \pm Standard Deviation & $\%$ \\
\hline Age (year) & 30 & $51.53 \pm 15,662$ & \\
\hline Range & & $18-75$ & \\
\hline Gender & 21 & & $70 \%$ \\
\hline Male & 9 & & $30 \%$ \\
\hline \multicolumn{4}{|l|}{ Female } \\
\hline Height (cm) & 30 & $160,57 \pm 8,037$ & \\
\hline Weight (kg) & 30 & $62.67 \pm 14,502$ & \\
\hline $\operatorname{BMI}\left(\mathrm{kg} / \mathrm{m}^{2}\right)$ & 30 & $24.26 \pm 5,158$ & \\
\hline $\begin{array}{l}\text { Pre-operative antiplatelet } \\
\text { consumption (days) }\end{array}$ & 14 & & $46.7 \%$ \\
\hline $\begin{array}{l}\text { Pre-operative anticoagulant } \\
\text { consumption (days) }\end{array}$ & 4 & & $13.3 \%$ \\
\hline $\begin{array}{l}\text { Cessationof pre-operative } \\
\text { antiplatelet (days) }\end{array}$ & 14 & $5.43 \pm 0,852$ & \\
\hline $\begin{array}{l}\text { Cessation of pre-operative } \\
\text { anticoagulant (days) }\end{array}$ & 4 & $5.5 \pm 1.000$ & \\
\hline \multicolumn{4}{|l|}{ Surgical procedures } \\
\hline ASD & 1 & & $3.3 \%$ \\
\hline CABG & 17 & & $56.7 \%$ \\
\hline$C A B G+A V R$ & 2 & & $6.7 \%$ \\
\hline MVR & 6 & & $20 \%$ \\
\hline TOF & 1 & & $3.3 \%$ \\
\hline VSD closure & 3 & & $10 \%$ \\
\hline Time on CPB (minute) & 30 & $116,57 \pm 41,831$ & \\
\hline The lowest temperature of $\mathrm{CPB}\left({ }^{\circ} \mathrm{C}\right)$ & 30 & $31.24 \pm 1,498$ & \\
\hline Total heparin during surgery (IU) & 30 & $11.933,33 \pm 4184,811$ & \\
\hline Total fluid running on CPB (mL) & 30 & $1.313,33 \pm 564,607$ & \\
\hline $\begin{array}{l}\text { Pre-operativethrombocyte } \\
\text { count }\left(10^{3} / \mu \mathrm{L}\right)\end{array}$ & 30 & $259,20 \pm 72,006$ & \\
\hline $\begin{array}{l}\text { Post-operative thrombocyte } \\
\text { count }\left(10^{3} / \mu \mathrm{L}\right)\end{array}$ & 30 & $191,37 \pm 71,187$ & \\
\hline $\begin{array}{l}\text { Intraoperative PRC needed } \\
\text { (blood bag) }\end{array}$ & 6 & $338,33 \pm 125,023$ & $20 \%$ \\
\hline \multicolumn{4}{|l|}{ Chest tube output (mL) } \\
\hline $1^{\text {st }}$ hour & 30 & $16.33 \pm 14,767$ & \\
\hline $2^{\text {nd }}$ hour & 30 & $14.77 \pm 10,559$ & \\
\hline $3^{\text {rd }}$ hour & 30 & $21.90 \pm 20,471$ & \\
\hline $4^{\text {th }}$ hour & 30 & $18.33 \pm 15,020$ & \\
\hline
\end{tabular}

BMI: Body Mass Index, ASD: Atrial Septal Defect, CABG: Coronary Artery Bypass Grafting, AVR: Aortic Valve Replacement, MVR: Mitral Valve Replacement, TOF: Tetralogy of Fallot, VSD: Ventricular Septal Defect, CPB: Cardiopulmonary Bypass, PRC: Packed Red Cell 


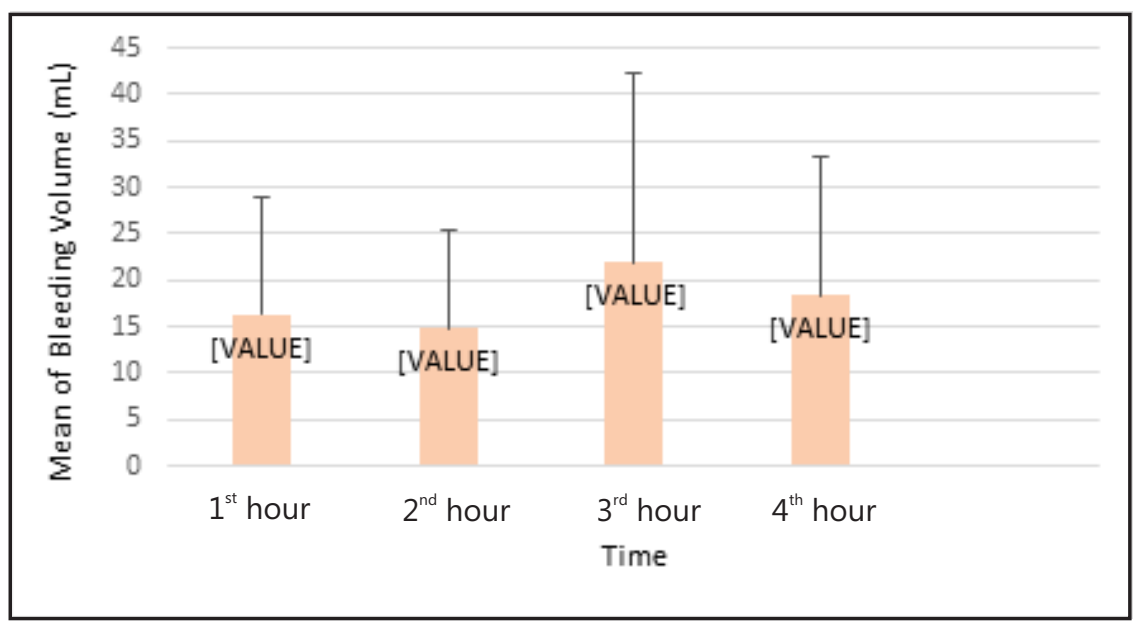

Figure 1. Mean of bleeding volume measurement at I, II, III, and IV hour

Table 2. Hypercoagulability criteria ${ }^{12}$

\begin{tabular}{|c|c|}
\hline LY30 < 8\% Along With: & Explanation \\
\hline$R$ time $>27$ minutes & Platelet hypercoagulability, \\
\hline $\mathrm{MA}>64 \mathrm{~mm}$ & $\begin{array}{l}\text { Hypocoagulability of coagulation factor } \\
\text { (enzymatic) }\end{array}$ \\
\hline R time 9-27 minutes & Platelet hypercoagulability \\
\hline $\mathrm{MA}>64 \mathrm{~mm}$ & \\
\hline R time $<9$ minutes & Hypercoagulability of coagulation factor \\
\hline $\mathrm{MA}<44 \mathrm{~mm}$ & (enzymatic) \\
\hline & Platelet hypocoagulability \\
\hline R time $<9$ minutes & Hypercoagulability of coagulation factor \\
\hline MA 44-64 mm & (enzymatic) \\
\hline R time $<9$ minutes & Hypercoagulability of coagulation factor \\
\hline $\mathrm{MA}>64 \mathrm{~mm}$ & (enzymatic) and platelet \\
\hline
\end{tabular}

The results of the TEG $R$ time value showed that 17 patients or $56.7 \%$ were in the normal range (9-12 minutes) and 13 patients or $43.3 \%$ had a value less than 9 minutes. The median value was 9.25 minutes (minimum of 4.2 minutes, maximum 15.6 minutes). The results of the $\mathrm{K}$ time value showed that 20 patients or $66.7 \%$ were in the normal range (2-9 minutes) and 10 patients or $33.3 \%$ had a value less than 2 minutes. The median value was 2.4 minutes (minimum of 1.2 minutes, maximum of 4.8 minutes). The results of the TEG $\alpha$ angle showed that 15 patients or $50 \%$ were within the normal range $\left(22-58^{\circ}\right)$ and values less than $22^{\circ}$. The median value was $58.35^{\circ}$ (minimum $29.8^{\circ}$, maximum $70.7^{\circ}$ ). The TEG MA results showed that 23 patients or $76.7 \%$ were in the normal range $(44-64 \mathrm{~mm})$ and 7 patients or $23.3 \%$ had MA values $>64 \mathrm{~mm}$. The median value was $57.95 \mathrm{~mm}$ (minimum $47 \mathrm{~mm}$, maximum $77 \mathrm{~mm}$ ). The TEG LY30 results showed that all patients $(n=30)$ or $100 \%$ were in the normal range $(0-8 \%)$ with median value of $0 \%$ (minimum $0 \%$, maximum $4 \%$ ).
The results of the Spearman correlation test showed that there was no significant correlation between TEG ( $R$ time, $K$ time, $\alpha$ angle, MA and LY30) and the volume of bleeding at I, II, III, and IV hours ( $p$ $>0.05$ ).

The results of this study also showed that 17 patients or $56.7 \%$ of the total TEG test results had hypercoagulability. Hypercoagulability criteria according to the TEG $\circledast 5000$ examination are described in Table 2 .

Bleeding is one of the most frequent complications after cardiac surgery using CPB. The bleeding criteria according to Colson et al. is, the bleeding volume $>1.5 \mathrm{~mL} / \mathrm{kgBW} /$ hour in 6 consecutive hours for 24 hours, whereas according to Bojar's criteria is a bleeding volume > 100 $\mathrm{mL} /$ hour, which requires blood component therapy. ${ }^{4,10}$

The results of this study indicated that there was no clinically significant bleeding in all samples, thus no intervention or special therapy was needed. The 
results showed an increase in the volume of bleeding at IV hours compared to I hour in some samples. In a good coagulation system, the bleeding volume should be reduced. This can be caused by a blood clot in the drain hose that fell off during manipulation of the tube. This released blood clot will increase the volume of bleeding measured in the container, so that it seemed as if there had been an increase in the volume of bleeding at IV hours, although the measured volume of bleeding was not clinically significant. The increased bleeding volume at IV hour was significantly correlated with prolonged PT value; however, this bleeding volume at IV hour was not clinically significant for the indication of hemostatic intervention therapy.

Haas et al. examined the use of the criteria of prolonged aPTT and PT values $\geq 1.5$ times of normal values to assess the occurrence of bleeding, and these criteria were used as a guide in administering hemostatic intervention therapy. ${ }^{11}$ This study results showed that patients with aPTT and PT values above the normal range had no clinically significant bleeding. Also, aPTT $\geq 1.5 x$ the upper limit of normal value did not show clinically significant bleeding to provide therapy according to the criteria of Colson et al. and Bojar. ${ }^{4,10}$

Previous studies have shown that aPTT and PT values usually increase after cardiac surgery. ${ }^{13,14}$ Ceke et al. compared the APTT and INR values in post-cardiac surgery patients with CPB (on-pump) and those without CPB (off-pump). The results showed that the aPTT value increased significantly in post-cardiac surgery patients using CPB (on-pump) compared to those who did not use CPB (off-pump). This is because the use of CPB can cause the phenomenon called "heparin rebound", a condition in which heparin is still found in the circulation 1-8 hours after neutralization with protamine. The more significant increase in aPTT value represents a condition of hypocoagulability, but there was no further explanation about the large volume of post-operative bleeding that occurred. ${ }^{13}$

Ozolina et al. showed that 25 of 83 patients had increased aPTT values after cardiac surgery using CPB. The increase in aPTT value might be due to hemodilution due to decreased coagulation factors during the use of CPB. However, this study did not find a significant correlation between aPTT value and 24-hour post-operative bleeding. ${ }^{6}$

This study showed increased APTT and PT values without clinically significant bleeding, even though the aPTT values increased by $\geq 1.5 \mathrm{x}$ the upper limit of normal. The increase in aPTT without significant bleeding can be caused by several conditions. First, it might be necessary to review the determination of the range of aPTT and PT values used in the laboratory in this study. This was because the results of aPTT $\geq 1.5 \times$ normal upper limit were not accompanied with significant bleeding requiring therapy according to the criteria of Haas et al. ${ }^{11}$

Second, the patient might have had an Antiphospholipid Syndrome (APS) that had not been diagnosed during hospitalization. Antiphospholipid syndrome is a coagulation disorder that shows abnormal results in the coagulation physiological test (in-vitro) and causes thrombosis (in-vivo). ${ }^{15}$ The frequency of APS to occur is $1-5 \%$ in healthy young people and $30 \%$ in patients with Systemic Lupus Erythematosus (SLE). ${ }^{16}$ Lupus anticoagulant is an antiphospholipid antibody that can cause an increase in aPTT, associated with the clinical manifestations of venous and arterial thrombosis. This abnormality needs to be proven by examining the dilute viper venom time (DVVT), anticardiolipin antibodies, $\beta 2 \mathrm{GPI}$ antibody, or the lupus anticoagulant assay. ${ }^{17}$ Massoudy et al. reported five cases of patients with APS who underwent heart surgery. Two patients with a diagnosis of APS were confirmed after surgery and after the patient died, while three patients were diagnosed during the hospitalization. Two people did not experience perioperative problems, while one person died after experiencing a thrombotic condition 10-day post-operation. ${ }^{18}$

Third, the patient might have had a deficiency in the contact system, such as factor FXII deficiency. Factor FXII deficiency or Hageman's factor deficiency is a rare and genetically inherited blood disorder that causes prolonged aPTT values without any tendency of bleeding. Clinical symptoms are usually absent; consequently, patients often go undiagnosed. The exact incidence rate in the general population is unknown, but it is estimated that about 1 of 1 million people develop this disorder. The researchers found that factor XII deficiency occurs due to a mutation in the F12 gene located on the long arm of chromosome 5 (5q33-qter). An examination of FXII activity is required to prove this. ${ }^{19} \mathrm{Upal}$ et al. reported one case of a patient with FXII deficiency who underwent cardiac surgery with CPB. These diagnosed disorders make it easier to safely administer heparin anticoagulants by monitoring heparin levels. ${ }^{20}$

An interesting thing found in this study was that more than half of the patients had hypercoagulability characteristics on the TEG test. 
More than half of these patients had a history of $C A B G$, whereas the rest of them had a history of valve surgery and TOF. This study results suggested that TEG was better in detecting hypercoagulability, consistent with the absence of clinically significant bleeding. This was in contrast to aPTT and PT values, which were normal and prolonged, and no clinically significant bleeding was found. This hypercoagulability condition may affect the clinical appearance of these patients; however, further investigation was still needed to find the cause and the clinical manifestations, which might emerge. Further research was needed to explain the mechanism by, which CPB can induce hypercoagulability in patients.

Hypercoagulability is a condition in which a person has the potential for thrombosis due to congenital and/or acquired defects. Hypercoagulability is involved in the pathogenesis of thromboembolic conditions such as myocardial infarction, ischemic stroke, pulmonary embolism, and Deep Vein Thrombosis (DVT). Genetically inherited causes of hypercoagulability include mutation of factor $\mathrm{V}$ Leiden, deficiency of protein $\mathrm{C}$, protein $S$, and antithrombin III, and hyperhomocysteinemia. One of the frequent causes is lupus anticoagulant. Pre-operative screening to detect causes of hypercoagulability is rarely recommended, due to the rare occurrence of hypercoagulability and its absent clinical manifestations. ${ }^{21,22}$

Bochsen et al. reported cases of patients undergoing cardiac surgery compared to patients as normal control. The results of the TEG test showed hypercoagulability characteristics in 6 of 22 patients (27\%) with a history of CABG compared to 1 hypercoagulability characteristic of 43 normal controls (2\%). ${ }^{23}$ Rafiq et al. reported $43.5 \%$ of post-CABG patients with the TEG test, which showed hypercoagulability characteristics. The authors then identified several factors associated with the pre-operative conditions of these patients. ${ }^{24}$

Hypercoagulability can also be caused by the use of $C P B$, but researchers have not found many theoretical references to the effect of using CPB on hypercoagulability conditions. Pagani et al. reported that $1 \%$ of patients died and $5 \%$ of patients had an ischemic stroke caused by thrombosis due to the use of CPB for cardiac surgery. ${ }^{25}$ Spaniel et al. performed a study about significant thrombin formation and fibrinolysis in patients with CPB. The CPB surface texture causes a "compensatory coagulation" phenomenon due to an increase in the population of activated macrophages and monocytes expressing tissue factors and proinflammatory cytokines on the CPB surface. The increase in tissue factor occurs continuously in circulation. ${ }^{26}$

\section{CONCLUSION AND SUGGESTIONS}

This study concluded that PT examination can be used to identify changes in the volume of bleeding at IV hours. TEG can provide a better representation of hypercoagulability in adult post-cardiac surgery patients with CPB. Further research was needed to determine the factors that influence hypercoagulability in post-cardiac surgery patients with CPB.

\section{REFERENCES}

1. Deppe AC, Carolyn W, Zimmermann J, Kuhn EW, Slottosch I, et al. Point of care TEG/ROTEM based coagulation management in cardiac surgery: A meta-analysis of 8,332 patients. Journal of Surgical Research, 2016; 203(2): 424-33.

2. Görlinger K, Shore-Lesserson L, Dirkmann D, Hanke $A A$, Rahe-Meyer N, et al. Management of hemorrhage in cardiothoracic surgery. Journal of Cardiothoracic and Vascular Anesthesia, 2013; 27(4): 20-34.

3. Sharma AD, Achi AA, Seccombe JF, Hummel R, Preston $M$, et al. Does incorporation of thromboelastography improve bleeding prediction following adult cardiac surgery?. Blood Coagulation and Fibrinolysis, 2014; 25 : 561-570.

4. Bojar RM. Manual of Perioperative care in adult cardiac surgery. $4^{\text {th }}$ Ed., Chelsea, Sheridan Books Incorporation, 2005; chapter 35: 131-155.

5. Neira VM, Sawchuk C, Bonneville KS, Chu V, Warkentin TE. Case report: Management of immediate post-cardiopulmonary bypass massive intra-cardiac thrombosis. Can J Anaesth, 2007; 54:461-6.

6. Ozolina A, Strike E, Sondore A, Vanags I. Coagulation tests and their association with post-operative blood loss after cardiac surgery with cardiopulmonary bypass. Acta Medica Lituanica, 2012; 19(3): 166-171.

7. Bolliger D, Tanaka KA. Point-of-care coagulation testing in cardiac surgery. Seminars in Thrombosis \& Hemostasis, 2017; 1-11.

8. Thakur M, Ahmed AB. A review of thromboelastography. International Journal of Perioperative Ultrasound and Applied Technologies, 2012; 1(1): 25-29.

9. Abdelfattah K, Cripps MW. Thromboelastography and rotational thromboelastometry use in trauma. International Journal of Surgery, 2016; 33: 196-201.

10. Colson PH, Gaudard P, Fellahi JL, Bertet H, Faucanie M, et al. Active bleeding after cardiac surgery: A prospective observational multicenter study. PLos One, 2016; 11(9): 1-14.

11. Haas T, Fries D, Tanaka KA, Asmis L, Curry S, et al. Usefulness of standard plasma coagulation tests in the 
management of perioperative coagulopathic bleeding: Is there any evidence?. British Journal of Anaesthesia, 2015; 114(2): 217-24.

12. Hypercoagulable States Basic Clinician Training Module 4, Available from : slideplayer.com (accessed 20 September, 2019).

13. Ceke LS, Imamovic S, Ljuca F, Jerkic Z, Imamovic G. Changes in activated partial thromboplastine time and international normalized ratio after on-pump and off-pump surgical revascularization of the heart. Bosn J Basic Med Sci, 2014; 14(2): 70-74.

14. Roy S, Saha K, Mukherjee K, Dutta S, Mukhopadhyay D, et al. Activation and coagulation and fibrinolysis during coronary artery bypass grafting: A comparison between on-pump and off-pump technique. Indian J Hematol Blood Trans, 2014;30(4): 333-341.

15. Esmon NL, Safa O, Smirnov MD, Esmon CT. Antiphospholipid antibodies and the protein C pathway. J Autoimmun, 2000; 15: 221-5.

16. Shi W, Krilis SA, Chong BH, Gordon S, Chesterman CN. Prevalence of lupus anticoagulant and anticardiolipin antibodies in a healthy population. Aust N Z J, 1990; 20: 231-6.

17. Smith LJ. Laboratory diagnosis of the lupus anticoagulant. Clin Lab Sci, 2017; 30(1): 7.

18. Massaoudy $\mathrm{P}$, Cetin SM, Thielmann M, Kienbaum $P$, Piotrowski JA, et al. Antiphospholipid syndrome in cardiac surgery-an underestimated coagulation disorder?. European Journal of Cardio-thoracic Surgery, 2005; 28: 133-137.

19. Bick RL. Disorders of thrombosis \& hemostasis. $3^{\text {rd }}$ Ed., Philadelphia, Lippincott Williams \& Wilkins, 2002; 126.
20. Upal V, Rosin M. Factor XII deficiency and cardiopulmonary bypass. The Journal of Extra Corporeal Technology, 2014; 46: 254-257.

21. McCrath DJ, Cerboni E, Frumento RJ, Hirsch A, Bennett-Guerrero. Thromboelastography maximum amplitude predicts post-operative thrombotic complication including myocardial infarction. Anesth Analg, 2005; 100: 1576-83.

22. Ackneck HE, Sileshi B, Parikh A, Milano CA, Welsby I, et al. Pathophysiology of bleeding and clotting in the cardiac surgery patient. Circulation, 2010; 122: 2068-2077.

23. Bochsen L, Nielsen AB, Steinbruchel DA, Johansson PI. Higher tromboelastograph platelet reactivity in cardiac surgery patients than in blood donors. Scand Cardiovascular J, 2007; 41: 321-4.

24. Rafiq S, Johansson PI, Ostrowski SR, Stissing T, Steinbruchel DA. Hypercoagulability in patients undergoing coronary artery bypass grafting: Prevalence, patient characteristics and post-operative outcome. European Journal of Cardio-Thorasic Surgery, 2012; 41: 550-555.

25. Pagani FD, Miller LW, Russell SD, Aaronson KD, John R, Boyle AJ, et al. Extended mechanical circulatory support with a continuous-flow rotary left ventricular assist device. J Am Coll Cardiol, 2009; 54: 312-321.

26. Spaniel TB, Chen JM, Oz MC, Stern DM, Rose EA, et al. Time-dependent cellular population of textured-surface left ventricular assist devices contributes to the development of a biphasic systemic procoagulant response. J Thorac Cardiovasc Surg, 1999; 118: 404-413. 